\title{
EUS-guided hepaticogastrostomy as a gateway to intermittent access for biliary leak management
}

Endoscopic ultrasound (EUS)-guided hepaticogastrostomy (HPG) is still unfairly confined to palliation of advanced malig-

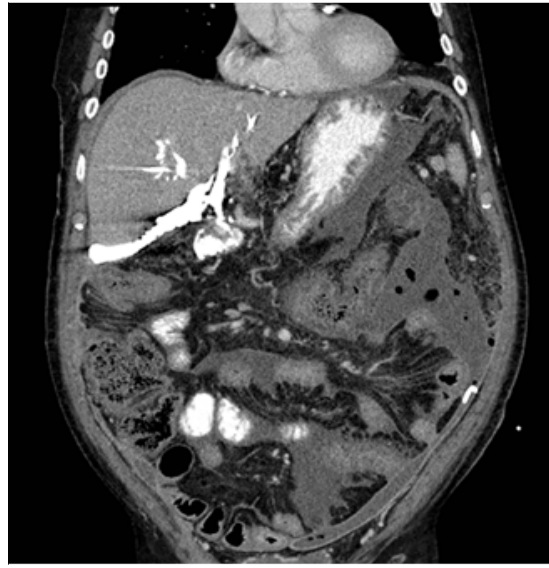

- Fig. 1 Abdominal computed tomography revealing a large subhepatic contrast leak upon injection through the percutaneously inserted biliary drain. nancies. However, this technique might be of significant help in benign indications, providing effective and safe longterm access to the biliary tree and facilitating the definitive treatment of biliary diseases [1 -4].

A 65-year-old patient with a history of pancreaticoduodenectomy was referred for a biliary leak following a recent redo hepaticojejunostomy ( $>$ Fig.1). Enteroscopy-directed endoscopic retrograde cholangiopancreatography (ERCP) was performed, with confirmation of the biliary leak and insertion of a 7-Fr doublepigtail stent. Unfortunately, this stent migrated distally. With the left-sided bile duct dilation and surgically altered anatomy in mind, EUS-guided antegrade stenting was attempted. The left main hepatic duct was accessed using a 196 needle ( Fig. 2); the guidewire was advanced into the small bowel, after which the tra-

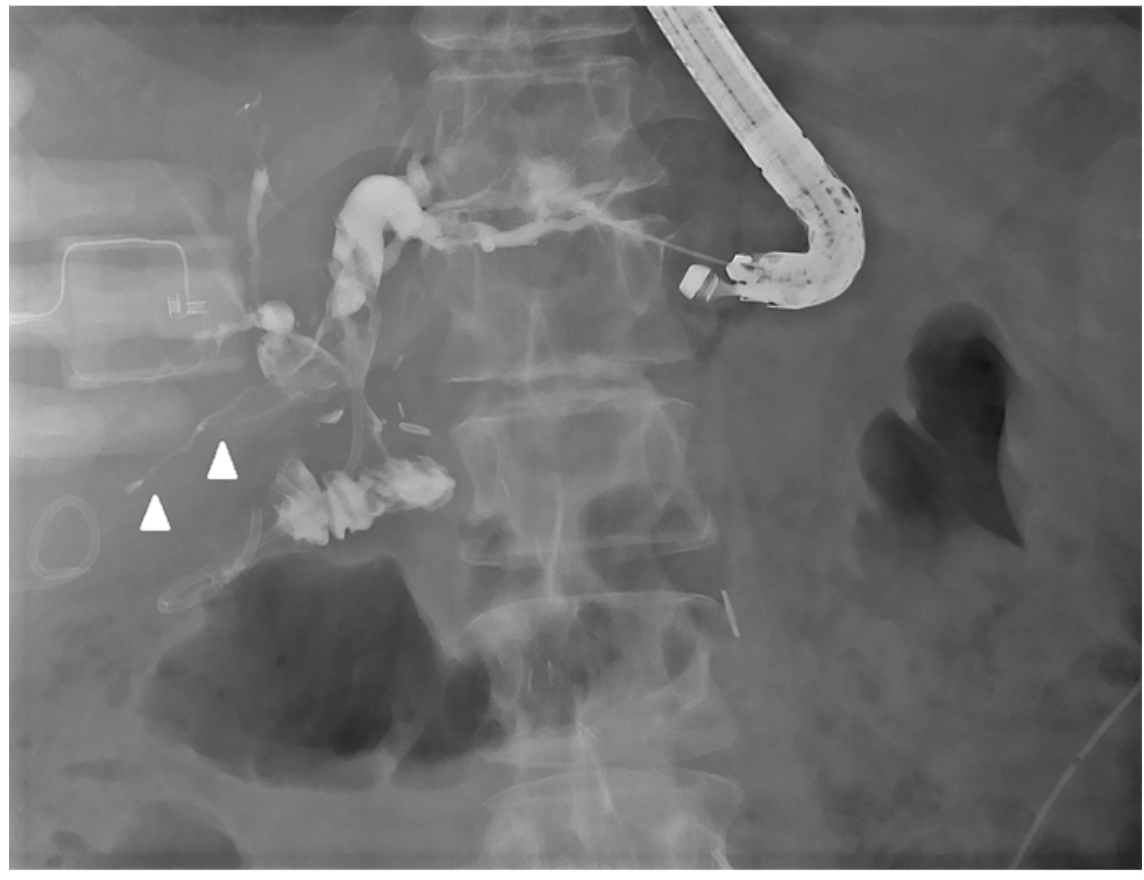

Fig. 2 Fluoroscopic image showing successful endoscopic ultrasound-guided access to the left hepatic duct using a 19 -gauge needle and 0.035 -inch guidewire. A linear contrast opacification can be appreciated just below the liver, compatible with the biliary leak (arrowheads). jectory was consolidated using a 6-Fr cystotome, and a fully covered self-expandable metal stent (FCSEMS) was placed. However, this stent migrated into the small bowel, and therefore an EUS-guided HPG was performed over the same guidewire (\$ Fig. 3 ) in an effort to provide immediate biliary drainage together with long-term access ( $\triangleright$ Video 1 ). Considering the benign indication, an FCSEMS $(10 \times 80 \mathrm{~mm})$ was used for EUS-guided HPG. A revision was performed 2 weeks later, with extraction of the FCSEMS and replacement with a double-pigtail stent $(10 \mathrm{Fr} \times 10 \mathrm{~cm})$, bridging the fistula ( $\triangleright$ Fig.4). A new revision was performed 3 months later that showed complete resolution of the biliary leak ( $\mathbf{F i g . 5}$ ), after which two double pigtails were inserted in similar fashion, to be finally extracted in 3 months' time.

Our case illustrates that in patients with benign indications and impossible/failed retrograde access, EUS-guided HPG may ensure an effective long-term gateway to definitive endoscopic treatment of bili-

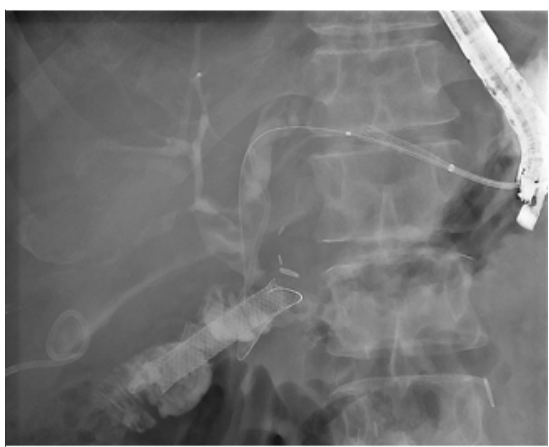

-Fig. 3 Fluoroscopic image revealing distal migration of the self-expandable metal stent (SEMS) into the small bowel lumen, while another fully covered SEMS is being placed into the left bile duct, creating an EUS-guided hepaticogastrostomy. Both the migrated SEMS and double-pigtail stent were scheduled for double-balloon enteroscopy-assisted retrieval after completion of endoscopic biliary leak treatment. 


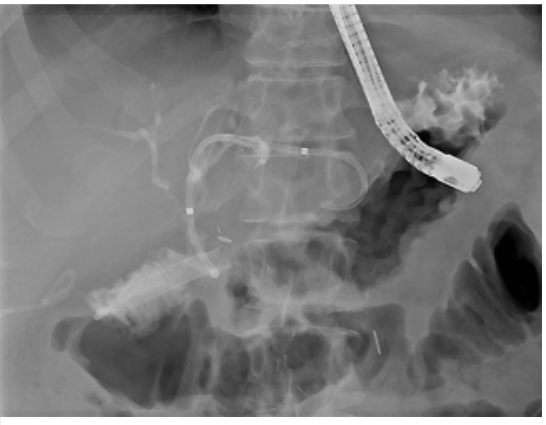

- Fig. 4 Revision 2 weeks after the index procedure and replacement of the fully covered self-expandable metal stent by a 10-cm double-pigtail stent.

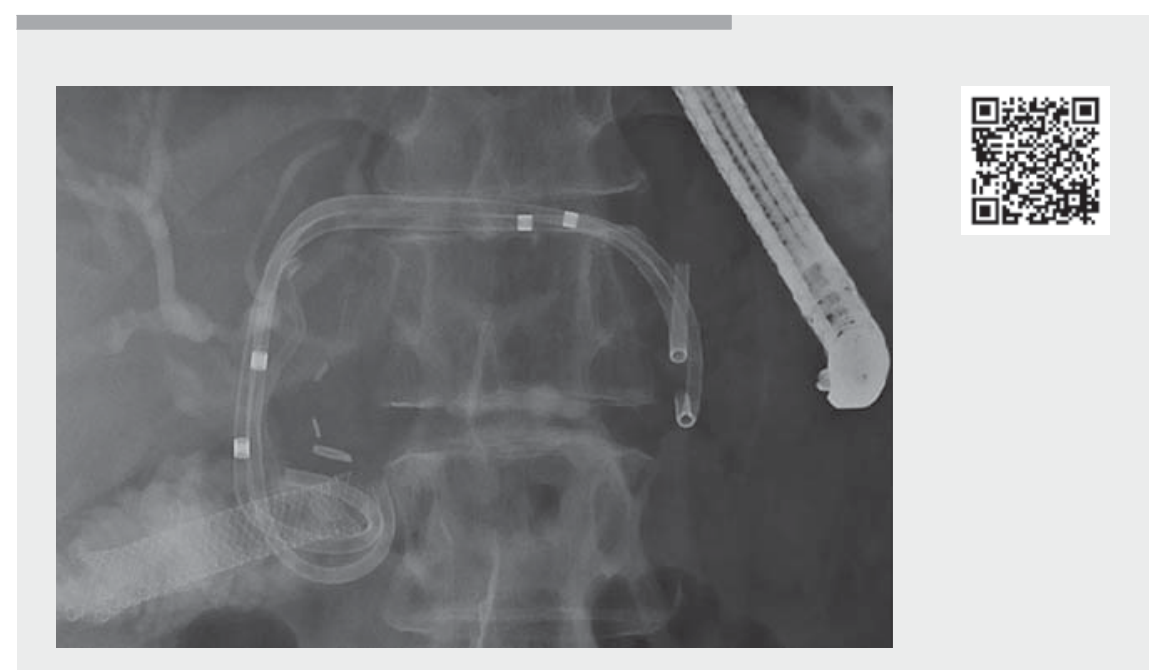

$\checkmark$ Video 1 Endoscopic ultrasound-guided hepaticogastrostomy for an anastomotic biliary leak.

ary diseases. In this context, double-pigtail stents can provide secure drainage and long-term patency as well as minimize the risk of migration.

\section{Endoscopy_UCTN_Code_CPL_1AK_2AI}

\section{Competing interests}

Michiel Bronswijk received grants from Prion Medical, Taewoong and Takeda. Giuseppe Vanella received grants from Mylan and Alfa Sigma. Baki Topal declares no potential conflicts of interest. Schalk van der Merwe holds the Cook and Boston-Scientific chair in interventional endoscopy and holds consultancy agreements with Cook, Pentax and Olympus.

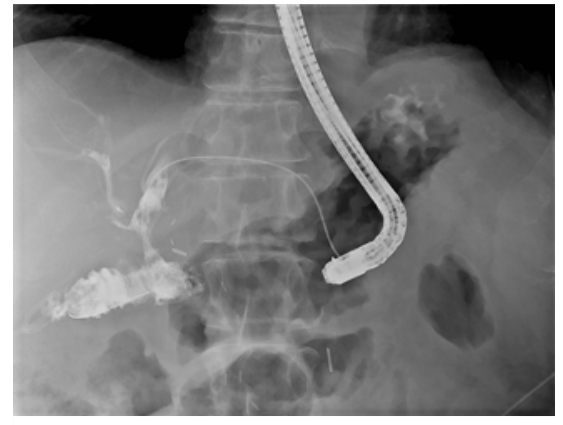

- Fig. 5 Second revision after 3 months showing complete resolution of the biliary leak, after which two new double pigtails were placed ultimately to be removed after 3 months.
Corresponding author

Michiel Bronswijk, MD

Imelda General Hospital, Imeldalaan 9, 2820 Bonheiden, Belgium

mjh.bronswijk@gmail.com

\section{References}

[1] Miranda-García P, Gonzalez JM, Tellechea J et al. EUS hepaticogastrostomy for bilioenteric anastomotic strictures: a permanent access for repeated ambulatory dilations? Results from a pilot study Endosc Int Open 2016; 4: E461-E465. doi:10.1055/s-0042103241

[2] Vanella G, Bronswijk M, van Malenstein $\mathrm{H}$ et al. EUS-guided intrahepatic access for retrograde, antegrade or transgastric biliary drainage: indications, efficacy and safety from an 8-year tertiary center experience. Gastrointestinal Endoscopy 2020; 49: AB93

[3] Nakai $\mathrm{Y}$, Kogure H, Isayama $\mathrm{H}$ et al. Endoscopic ultrasound-guided biliary drainage for benign biliary diseases. Clin Endosc 2019; 52: 212-219. doi:10.5946/ ce. 2018.188

[4] Okuno N, Hara K, Mizuno N et al. Advanced technique for biliary stricture diagnosis using endoscopic ultrasound (EUS)-guided hepaticogastrostomy. Endoscopy 2017; 49: E60-E61. doi:10.1055/s-0042-123498

\section{Bibliography}

Endoscopy 2021; 53: E427-E428

DOI 10.1055/a-1327-1849

ISSN 0013-726X

published online 27.1.2021

(c) 2021. Thieme. All rights reserved.

Georg Thieme Verlag KG, Rüdigerstraße 14, 70469 Stuttgart, Germany

Michiel Bronswijk ${ }^{1,2} \odot$, Giuseppe Vanella ${ }^{3} \odot$, Baki Topal ${ }^{4}$, Schalk Van der Merwe ${ }^{1}$

1 Department of Gastroenterology and Hepatology, University Hospitals Leuven, Belgium

2 Department of Gastroenterology, Imelda General Hospital, Bonheiden, Belgium

3 Pancreatobiliary Endoscopy and EUS Division, IRCSS San Raffaele Scientific Institute, Vita-Salute San Raffaele University, Milan, Italy

4 Department of Hepatobiliary Surgery, University Hospitals Leuven, Belgium

\section{ENDOSCOPY E-VIDEOS \\ https://eref.thieme.de/e-videos}

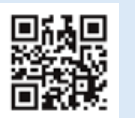

Endoscopy E-Videos is a free access online section, reporting on interesting cases and new techniques in gastroenterological endoscopy. All papers include a high quality video and all contributions are freely accessible online.

This section has its own submission website at https://mc.manuscriptcentral.com/e-videos 